
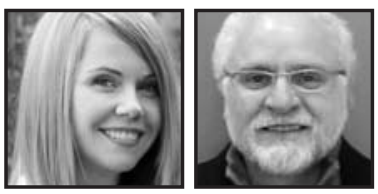

\title{
Preparing Teachers for Inclusive Classrooms: Introducing the Individual Direct Experience Approach
}

Jodi Peebles, University of Alberta

Sal Mendaglio, University of Calgary

\section{ABSTRACT}

Inclusion is a contemporary educational movement impacting the role of the classroom teacher. As a result, teacher education programs have made attempts to incorporate inclusive education as part of their curricula. An analysis of the literature reveals that inclusion training has favorable effects on the attitudes of preservice teachers, but has little effect on their perceptions of preparedness to teach in inclusive classrooms. A common complaint is that the focus is heavily weighted on theory, as opposed to practical experience. To address such concerns, the authors recommend the Individual Direct Experience Approach (IDEA) as an innovative approach to preparing teachers for inclusive classrooms.

\section{Introduction}

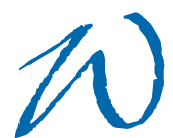

ith social justice at the international forefront of educational agendas, the inclusion of students with exceptionalities in the general education classroom has propelled a worldwide political and philosophical movement. In an inclusive model, students with exceptional needs are educated alongside their peers in the general classroom as the first placement option to be considered. The inclusion movement is an impetus for change, not only in educational policies, but also in the role and expectations of the classroom teacher. Inclusion has a tremendous impact on general classroom teachers as they are increasingly faced with the challenge of meeting a wide range of student needs through inclusive practices. More than ever 
before, classroom teachers are required to understand a multitude of exceptionalities, manage a diverse classroom, implement differentiated instructional strategies, and make appropriate accommodations for individual needs. Not surprisingly, it has been found that the general classroom teacher has a profound impact on the success of inclusive education (Forlin, Loreman, Sharma, \& Earle, 2009; Winzer \& Mazurek, 2011); therefore, teacher preparation for inclusion is critical.

In response to the inclusion movement, post-secondary institutions have recognized their role in preparing preservice teachers with the knowledge, skills, and attitudes to successfully manage diverse groups of learners (Ashan, Sharma, \& Deppeler, 2012; Lancaster \& Bain, 2010). There is an urgent need to equip teachers to work in diverse settings, and it is evident that most post-secondary institutions offer some form of inclusion training as part of their teacher preparation program. The following section outlines a selection of research, and captures recurring themes based on a comprehensive review of the current literature surrounding approaches to inclusion training.

\section{The Impact of Inclusion Training}

\section{Preservice Teacher Attitudes}

There is much evidence that inclusion training has a positive impact on preservice teachers' attitudes toward inclusion. Sze (2009) conducted an international review of the research in this area and determined that teacher education for inclusion brought an awareness of exceptionalities, which formed positive attitudes in preservice teachers toward inclusion. Additional research studies support these findings. For example, Sharma, Forlin, and Loreman (2008) conducted a large study with participants from five post-secondary institutions located in Canada, Hong Kong, Australia, and Singapore. The results found that single unit courses and infused approaches, where inclusion training is included in all course work, were both effective for espousing positive changes in attitudes. Kim's (2011) study also demonstrated increases in positive attitudes from both single-unit courses and an infused approach. Swain, Nordness, and LeaderJanssen's (2012) study found that a special education course, paired with 24 hours of field experience, significantly influenced positive attitude changes in preservice teachers. Lambe's (2007) study examined the changes in preservice teachers' attitudes after completing a post-graduate diploma in education in conjunction with a field experience. The results indicated that the program had a positive effect on preservice teachers' attitudes for teaching in inclusive settings and that the positive attitudes 
significantly increased after the field experience component. A study conducted by Boling (2007) provided an in-depth description of one preservice teacher's change in attitude towards inclusion as she participated in an inclusion course combined with field experiences. At the onset of the study, the participant expressed feelings of confusion, concern, nervousness, and generally struggled with the idea of inclusion. A key turning point for her positive change in attitude was her field experience component, which allowed her to interact with students with various exceptionalities.

Based on a comprehensive analysis of the literature, there is a vast amount of research on the impact that inclusion training has on preservice teacher attitudes and a general consensus in the field that teachers feel positively about the idea of inclusion.

\section{Perceptions of Preparedness}

While positive attitudes may be able to transcend philosophical barriers to inclusion, they may not always translate into feeling prepared for the reality of inclusive teaching. For example, a review conducted by Avramidis and Norwich (2002) concluded that although most teachers held positive attitudes toward inclusion, teachers did not feel prepared for teaching students with exceptional needs, especially in the case of students with severe learning difficulties and behavioral/emotional disorders. A qualitative study conducted by Fayez, Dababneh, and Jumiaan (2011) reported that preservice teachers held strong and positive attitudes about the philosophy of inclusion as an entitlement of children with special needs. However, when asked about their preparedness to implement inclusion, the participants felt their mandatory inclusion course, while adding to their knowledge base, only provided a very narrow understanding of practical skills. Another qualitative study found that a single-unit course on inclusion positively changed preservice teachers' perceptions about inclusion; however, participants overwhelmingly indicated that they still required additional knowledge and skills in order to "operationalize their changed perceptions and beliefs" (McCray \& McHatton, 2011, p. 149). Hodkinson's (2006) study found similar findings and concluded that firstyear teachers felt their preservice training provided them with a good understanding of the theory of inclusive education, however their understanding of the practical delivery was limited. Moore-Hayes' (2008) study reported that preservice teachers cited the need for more preparation and experience in order to feel prepared for working with students with exceptional needs. Additionally, in a study conducted by Forlin and Chambers (2011), the researchers discovered that a unit of study in inclusive education increased preservice teachers' knowledge and their confidence as teachers. In contrast, it also increased their levels of stress in teaching students with disabilities. 


\section{Conclusions Drawn From the Literature Reviewed}

The selection of reviews and empirical studies provide evidence that while teacher training for inclusion develops positive attitudes and theoretical knowledge, the lack of practical skill development and exposure to students with exceptional needs have a negative impact on perceptions of preparedness.

These findings should be of concern for teacher educators. Although positive attitudes can create the right climate for inclusion, it is not sufficient for preparing future teachers for the realities of inclusive teaching. Burton and Pace (2009) suggested that having positive attitudes cannot compensate for insufficient preparation, while Lancaster and Bain (2010) concurred that a sense of preparation is not contingent on attitudes alone, but that preservice teachers must also feel they have the strategies and the capability to execute the necessary practices.

From this investigation it can be substantiated that there are obvious gaps in teacher preparation programs. Teacher educators should view these gaps as a major roadblock to advancing the actualization of inclusion at the very basic level: the general education classroom. To ensure a better match between teacher preparation and the realities of inclusive classrooms, changes to the current approaches are necessary and critical. Based on our review of literature and experience as teacher educators, we conclude that adding authentic practical experiences to the existing courses in inclusion will benefit preservice teachers. Practical supervised experiences will add a sense of preparedness to their positive attitudes toward teaching in inclusive classrooms.

\section{Recommendations: Experience and Education}

As a preamble to proposing a recommendation for teacher education for inclusion, it is useful to consider and discuss the meaning of experience and education. Decades ago, renowned philosopher, John Dewey (1938) defined traditional education as one that relies on bodies of knowledge that have been worked out in the past, and the chief business of teachers and schools is to transmit this information to novice learners. In traditional education, the focus of curricula design is on content and subject, and teachers are the knowing agents of the content while students are the receptacles for which to store this information. The information is taught as a static, finished product. According to Dewey, traditional education is critiqued for its imposition and funneling of adult knowledge on less experienced learners, resulting in a gulf between the 
knowledge the teacher holds and the lived experience of the novice learner. This gulf is described as being so wide that "the very situation forbids much active participation by pupils in the development of what is taught" (Dewey, 1938, p. 19). Oddly enough, over 70 years later, this concept parallels the current concern in teacher education for inclusion.

Dewey (1938) attempted to explain what constitutes a "new," progressive education in a positive and constructive manner, rather than simply rejecting the traditional education. Dewey asserted that amid all uncertainties, one permanent frame of reference exists: the organic connection between education and personal experience. Therefore, Dewey's progressive education is centered on students acquiring knowledge from within and from experience, rather than from the outside through texts and teachers. This is not to reject teachers and theoretical knowledge (Dewey, 1904); the critique here lies in the process of transmission and the focus on the past rather than the present. Progressive education explains how a learner can translate static knowledge from the past into a potent instrument for the present through experience. In other words, experience closes the gap between the archived past and the living presentessentially it negotiates and narrows the gap between theory and practice.

This concept can be useful for designing programs for teacher education. We recommend that in preparing teachers for inclusive classrooms, teacher education programs should incorporate opportunities for direct experiences with students who have exceptional needs during field experiences. A recent study gathered opinions from 124 faculty members across the United States, where the majority considered field experiences to be a leading example in teacher training for inclusion (Harvey, Yssel, Bauserman, \& Merbler, 2010). Not only is this the opinion of faculty members, but research also demonstrated that when teachers were asked about their most preferred methods of preparation for teaching diverse learners, they suggested that direct teaching experiences with students with special needs was favored (Avramidis \& Norwich, 2002; Jobling \& Moni, 2004). One study of early childhood preservice teachers found that inclusive settings for field experiences could link inclusive coursework and fieldwork (Voss \& Bufkin, 2011). Moreover, Rose and Garner (2010) stressed the importance of practical, school-based experiences as an addition to the theoretical base of university inclusion courses. In fact, one of the leading researchers in this area argued that field experience opportunities and direct contact with students with special needs may be the "only meaningful solution" (Loreman, 2010) to improve inclusion training. 
However, some caution and careful consideration should be put forth given that field experiences do not always offer the optimum environment for practicing inclusive skills. For example, Jobling and Moni's (2004) study revealed that some participants felt they had limited contact with the special-needs students during their practicum because they "always had an aide with them" (p. 13). Also, Atay (2007) postulated that not every practicum setting is a model of good practice and that factors and experiences vary greatly. Yet another study suggested that placement schools should have a sufficient number of students with exceptional needs in their schools, as criterion for selection, in order to ensure more interactions and hands-on experience for preservice teachers (Lombardi \& Hunka, 2001). However, it was also recognized that it is often the case that the number of schools offering field experience placements is insufficient, leaving universities with little choice. Our own experiences as teacher educators confirm that when field experiences do not include specific guidelines for working with students with exceptional needs, preservice teachers often have limited exposure to-and practice with—-these students.

A solution to this issue may be to develop a more systematic and consistent approach to field experiences through well-structured, meaningful expectations. Such an approach may ensure that preservice teachers are realizing the full potential of the field experience as a training opportunity for inclusion. One such approach is the Individual Direct Experience Approach.

\section{Individual Direct Experience Approach}

The Individual Direct Experience Approach (IDEA) was developed by the first author, through her work with preservice teachers, as a systematic, meaningful approach to teacher preparation for inclusion (see Figure 1). IDEA is designed to be implemented during a preservice teacher's field experience, ideally an extended field experience of six to 12 weeks. It consists of having preservice teachers work individually and directly with one student with exceptional needs, as a living case study, throughout the duration of their field experience. Essentially, IDEA allows preservice teachers to experience direct interactions with a student with exceptional needs and to apply the knowledge and skills learned from these interactions to make appropriate adaptations or modifications to whole class lessons. This scaffolded process allows preservice teachers to understand the "how" and "why" of differentiating instruction and make accommodations for exceptional learners. The primary objectives of IDEA are to develop practical inclusive teaching skills and to allay preservice teachers' anxieties regarding working with students with exceptional needs. The specific expectations of 
IDEA are presented below, and an illustrative example will demonstrate the application of IDEA to a field experience.

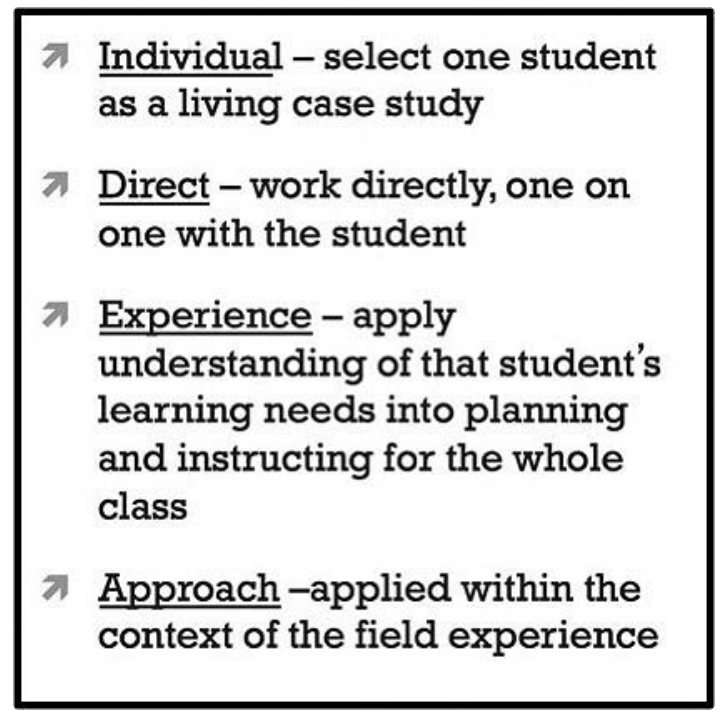

Fig. 1: Individual direct experience approach for teacher preparation for inclusion

\section{Expectations of IDEA}

IDEA requires preservice teachers to choose one student with exceptional needs from their classroom placement as a "living case study" during their field experience. The criteria for selecting students are that they have unique educational needs and require differentiated instruction or other forms of adaptations or modifications. It is certain that in every classroom at least one student can be identified, in consultation with the mentor teacher, as an appropriate living case for IDEA. After the living case is established, the preservice teacher is expected to fully and deeply understand the individual education plan (IEP) and/or the learning profile of this student, including prior educational experiences and assessment. Preservice teachers are also required to research the student's exceptionality and communicate with the student's teacher, teacher assistant, parents, and other members of the school support team in order to have a global understanding of the student. Following this background research, the key expectation is for the preservice teacher to engage in individual, direct experiences with the student for the duration of his or her field experience. A recommended frequency of the interactions would be two to three times per week for 15- to 30-minute sessions. Examples of interactions include guided literacy, individual conferencing, and 
direct instruction. Preservice teachers will keep a descriptive log and journal describing the direct experience interactions. Journal entries should include reflections about what works, what does not, and how the student learns best. There should also be opportunities for collaboration with the mentor teacher, university facilitator, and with other colleagues and preservice teachers. With IDEA, preservice teachers will be expected to plan and teach whole-class lessons up to a maximum of $80 \%$ of the instructional day in order to provide time for the individual interactions.

Prior research has demonstrated that direct experience with exceptional-needs students during training increases preservice teachers' preparedness for teaching in inclusive classrooms (Burton \& Pace, 2009; Forlin et al., 2009; Jung, 2007, Voss \& Bufkin, 2011). Peebles and Mendaglio's (2014) study demonstrated that, during a field experience, as preservice teachers spent more time with direct, individual instruction with students with exceptional needs, and less time with observation and wholeclass instruction, their self-efficacy for inclusive teaching was more likely to increase. IDEA differs from other approaches that use experience as a form of preparing teachers to work with exceptional students. For example, some programs have made attempts with "simulated" student case studies as a component of inclusion courses; however, it is acknowledged that the artificiality of the situation is itself a limitation (Pearson, 2007). Other programs have included practical experiences in the form of instructional tutoring (Burton \& Pace, 2009), after-school programs (Lancaster \& Bain, 2010), community involvement (Chambers \& Forlin, 2010), and visits to classrooms to work with groups of gifted students (Chamberlin \& Chamberlin, 2010). However, these programs did not provide the opportunity to subsequently teach these students within the broader context of a whole-class setting, which is the crux of effective inclusive teaching. A fictionalized illustrative example, based on the authors' experiences with preservice teachers, will demonstrate how IDEA can be applied.

\section{IDEA in Action}

Kim (all names are pseudonyms) is about to begin her nine-week final field experience in a grade three classroom. Many emotions run high, including her excitement to meet her students and her mentor teacher, Mr. Smith. Kim is also very nervous. She does not have a lot of experience working with children, and she has no prior experience with students with exceptional needs. She has talked with many of her classmates and their concerns are similar: Will I be able to manage and meet the needs of a diverse range of abilities and exceptionalities? I really want to include all students in my classroom activities, but can I really do it? 
As part of Kim's field experience, she is expected to choose a "living case study" in order to work directly with a student with exceptional needs. In her first week, with the help of Mr. Smith and the permission of the student's parents, Kim chooses Dillon. Dillon is an eight-year-old autistic boy and requires a full-time teacher's assistant, Mary. Mr. Smith feels that if Kim can understand Dillon's learning needs and behaviors, she will have a much easier time including him in her lessons. Mary is thrilled with this new approach. She shared with Kim that last year Dillon was often excluded from wholeclass lessons because the mentor teacher felt he was "too much work" for the student teacher-and that Mary could easily "look after" him during lessons.

During the first week of her field experience, Kim reads Dillon's comprehensive IEP, researches autism, talks to Mary and Mr. Smith, and meets Dillon's parents. After meeting his parents and hearing their story, Kim clearly understands the importance of meaningfully including Dillon in the classroom with his peers. She learns that Dillon's parents' main goals for him are to learn appropriate social skills, make friends, and learn to communicate with his iPad. She also observes Mary working with Dillon and begins to understand how to communicate with him and how to anticipate situations that cause frustration. She also learns that Dillon has a great number of strengths; he has a sense of humor, loves cars and trucks, and has a strong visual memory.

During this first week, Kim also observes her mentor teacher teaching the whole class and begins to plan for the classes that she will be taking over. The expectation is that she will take over approximately $80 \%$ of the classroom teaching by the halfway point in her field experience. While Mr. Smith is teaching the other $20 \%$ of instructional time, Kim has opportunities for her direct interactions with Dillon.

Over the remainder of her field experience, Kim spends approximately two 30-minute sessions with Dillon each week. The interactions take place within the classroom where Kim works directly with Dillon on a specific skill or with his communication program on his iPad. At one cohort meeting with her university facilitator, Kim expresses how valuable she feels the direct experience has been. "I am so comfortable interacting with Dillon. I've learned how to communicate with him on his iPad, and I can see that routine and structure are very important." Kim continues to share what she has learned about Dillon's communication skills, social skills, and his sensory therapy. "I feel that I can effectively plan modifications to my lessons in order to meaningfully include Dillon in the activities."

Near the end of her field experience, Kim is observed by her university facilitator while teaching a science lesson on rocks and minerals. The lesson includes interactive 
learning centers where the students were asked to classify rocks. Dillon is included with a small group of students. This group is given a cue card that Kim has prepared with "yes"/"no" questions that Dillon can answer on his iPad. At one point during the lesson, Kim intuitively moves Dillon to another group in order to remain longer at a particular center that she knows he is enjoying. Kim later explained that she knew the quick changing of centers would likely frustrate him as she has a very good grasp of what triggers some of his behaviors.

On Kim's final day, she discusses with Mr. Smith the benefits of the living case study expectation of her field experience. She expresses how the individual, direct experience eased her anxiety about working with students with exceptional needs. She also feels that she could translate what she has learned about inclusive teaching practices to other students with exceptional needs within her own future classroom. Mr. Smith agrees that the systematic approach was an effective way to connect the theory of inclusive practice to the realities of the classroom.

\section{Conclusion}

There is a consensus that best practice for preparing teachers for inclusion is a pressing issue for teacher educators. Field experience is an essential ingredient for teacher preparation, including the preparation of teachers for the inclusive classroom. While experience with students with exceptional needs has been accepted as benefitting preservice teachers, it is not always intentionally incorporated into field experiences. IDEA is an approach to systematically introduce preservice teachers to teaching in the inclusive classroom. Not only does IDEA provide preservice teachers with the opportunity for interacting with students with exceptional needs, but it also requires that knowledge gleaned from these interactions will be implemented in wholeclass instruction. As such, IDEA represents a closer approximation of the demands of the inclusion classroom than isolated direct experiences. In addition to providing guidance as to how inclusion is practiced, anxiety about working with students with exceptional needs may be lessened.

Future research in this area could address some of the potential limitations or unanswered questions related to IDEA. For instance, it would be valuable to research how the impact of IDEA applies to other inclusive settings, as student demographics vary greatly from classroom to classroom. Also, to provide validation to the approach, longitudinal studies could determine if the impact of IDEA is sustainable as preservice 
teachers enter the profession and progress through their careers. Qualitative studies could provide insight into the experience of IDEA and the nature of the impact on preservice teachers' preparation for inclusive teaching. Given the existing research in this area, IDEA is a promising starting point for structuring intentional direct experiences into inclusion training for future teachers.

\section{References}

Ashan, M., Sharma, U., \& Deppeler, J. (2012). Challenges to prepare pre-service teachers for inclusive education in Bangladesh: Beliefs of higher educational institutional heads. Asia Pacific Journal of Education, 32(2), 241-257.

Atay, D. (2007). Beginning teacher efficacy and the practicum in an EFL context. Teacher Development, 11(2), 203-219.

Avramidis, E., \& Norwich, B. (2002). Teachers' attitudes towards integration/inclusion: A review of the literature. European Journal of Special Needs Education, 17(2), 129-147.

Boling, E. (2007). "Yeah, but I still don't want to deal with it". Changes in a teacher candidate's conceptions of inclusion. Teaching Education, 18(3), 217-231.

Burton, D., \& Pace, D. (2009). Preparing preservice teachers to teach mathematics in inclusive classrooms: A three-year case study. School Science and Mathematics, 109(2), 108-115.

Chamberlin, M., \& Chamberlin, S. (2010). Enhancing preservice teacher development: Field experiences with gifted students. Journal for the Education of the Gifted, 33(3), 381-416.

Chambers, D., \& Forlin, C. (2010). Initial teacher education and inclusion: A triad of inclusive experiences. In C. Forlin (Ed.), Teacher education for inclusive education: Changing paradigms and innovative approaches (pp. 74-82). New York: Routledge.
Dewey, J. (1904). The relation of theory to practice in education. In C. A. McMurry (Ed.), The relation of theory to practice in the education of teachers (Third yearbook of the National Society for the Scientific Study of Education, Part I, pp. 9-30). Chicago: The University of Chicago.

Dewey, J. (1938). Experience and education. New York: Kappa Delta Pi.

Fayez, M., Dababneh, K., \& Jumiaan, I. (2011). Preparing teachers for inclusion: Jordanian preservice early childhood teachers' perspectives. Journal of Early Childhood Teacher Education, 32(4), 322-337.

Forlin, C., \& Chambers, D. (2011). Teacher preparation for inclusive education: Increasing knowledge but raising concerns. Asia-Pacific Journal of Teacher Education, 39(1), 17-32.

Forlin, C., Loreman, T., Sharma, U., \& Earle, C. (2009). Demographic differences in changing preservice teachers' attitudes, sentiments and concerns about inclusive education. International Journal of Inclusive Education, 13(2), 195-209.

Harvey, M. W., Yssel, N., Bauserman, A. D., \& Merbler, J. (2010). Preservice teacher preparation for inclusion: An exploration of higher education teacher-training institutions. Remedial and Special Education, 31(1), 24-33.

Hodkinson, A. (2006). Conception and misconceptions of inclusive education: A critical examination of final-year teacher trainees' knowledge and understanding of inclusion. Research in Education, 76, 43-55. 
Jobling, A., \& Moni, K. (2004). "I never imagined I'd have to teach these children: Providing authentic learning experiences for secondary pre-service teachers in teaching student with special needs. Asia Pacific Journal of Teacher Education, 32(1), 5-22.

Jung, W. S. (2007). Preservice teacher training for successful inclusion. Education, 128(1), 106-113.

Kim, J. R. (2011). Influence of teacher preparation programmes on preservice teachers' attitudes toward inclusion. International Journal of Inclusive Education, 15(3), 355-377.

Lambe, J. (2007). Northern Ireland student teachers' changing attitudes towards inclusive education during initial teacher training. International Journal of Special Education, 22(1), 59-71.

Lancaster, J., \& Bain, A. (2010). The design of preservice inclusive education courses and their effect on self-efficacy: a comparative study. Asia-Pacific Journal of Teacher Education, 38(2), 117-128.

Lombardi, T. P., \& Hunka, N. J. (2001). Preparing general education teachers for inclusive classrooms: Assessing the process. Teacher Education and Special Education, 24(3), 183-197.

Loreman, T. (2010). A content-infused approach to pre-service teacher preparation for inclusive education. In C. Forlin (Ed.), Teacher education for inclusion: Changing paradigms and innovative approaches (pp. 56-64). New York: Routledge.

McCray, E., \& McHatton, P. (2011). "Less afraid to have 'them' in my classroom": Understanding pre-service general educators' perceptions about inclusion. Teacher Education Quarterly, 38(4), 135-155.

Moore-Hayes, C. T. (2008). Teacher-efficacy: Exploring preservice and beginning teachers' perceptions of preparedness to teach. Dissertation Abstracts International, 68(11), i-150.
Pearson, S. (2007). Exploring inclusive education: Early steps for prospective secondary school teachers. British Journal of Special Education, 34(1), 25-32.

Peebles, J. L., \& Mendaglio, S. (2014). The impact of direct experience on preservice teachers' self-efficacy for teaching in inclusive classrooms. International Journal of Inclusive Education. Advance online publication. doi: 10.1080/13603116.2014.899635

Rose, R., \& Garner, P. (2010). The professional learning of teachers through experience in an international and intercultural context. In C. Forlin (Ed.), Teacher education for inclusion: Changing paradigms and innovative approaches (pp. 23-33). New York: Routledge.

Sharma, U., Forlin, C., \& Loreman, T. (2008). Impact of training on pre-service teachers' attitudes and concerns about inclusive education and sentiments about persons with disabilities. Disability \& Society, 23(7), 773-785.

Swain, K., Nordness, P., \& Leader-Janssen, E. (2012). Changes in preservice teacher attitudes toward inclusion. Preventing School Failure, 56(2), 75-81.

Sze, S. (2009). A literature review: Pre-service teachers' attitudes toward students with disabilities. Education, 130(1), 53-56.

Voss, J., \& Bufkin, L. (2011). Teaching all children: Preparing early childhood preservice teachers in inclusive settings. Journal of Early Childhood Teacher Education, 32(4), 338-354.

Winzer, M., \& Mazurek, K. (2011). Canadian teachers' associations and the inclusive movement for students with special needs. Canadian Journal of Educational Administration and Policy, 116(1-24). 


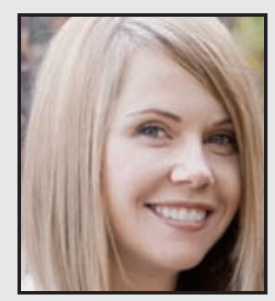

Jodi Peebles, EdD, is an instructor of educational psychology with the University of Alberta. Dr. Peebles has also taught graduate-level inclusive education courses for the University of British Columbia - Okanagan. She has a variety of experience in the field of inclusive education as a special education teacher and inclusive education facilitator. Her research interests include teacher preparation for inclusion, adaptations for exceptional students in the classroom, and teacher self-efficacy.

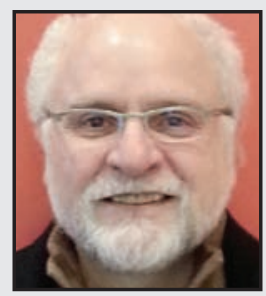

Sal Mendaglio, PhD, is a professor in the Faculty of Education, University of Calgary. Dr. Mendaglio also has extensive experience in teacher preparation including teaching and administration. Among his interests are teaching and counseling children with exceptional needs, with particular focus on students who are gifted. 